\title{
Modelo espacial para seleção de áreas adequadas à expansão urbana baseado em Avaliação Multicritério e Sistemas de Informação Geográfica. Caso do Município de Monte Belo do Sul, RS.
}

\author{
Spatial model for selection of suitable areas for urban expansion based on Multi \\ criteria Evaluation and Geographic Information Systems. A case study of Monte \\ Belo do Sul, Southern Brazil.
}

Kledson Róber Grabski ${ }^{1}$

Flávia Farina²(*)

\section{Resumo}

Atualmente, o crescimento urbano tem se configurado como um problema, por vezes, sem controle, ocasionando a expansão desordenada e descontínua, alheia aos padrões de segurança e sustentabilidade. Nesse sentido, este trabalho tem por objetivo propor um modelo espacial baseado em SIG, para subsidiar a indicação de áreas adequadas para expansão urbana. A implementação do modelo teve como área-teste o Município de Monte Belo do Sul, localizado na Região Metropolitana da Serra Gaúcha (RS). Para tal, inicialmente, foram definidos critérios que representam as características necessárias de uma área deve possuir para que possa ser ocupada. A espacialização e a modelagem desses critérios são realizadas em ambiente SIG (ArcGIS e IDRISI), onde cada variável pertinente compõe um plano de informação (PI) temático. Assim, o banco de dados é composto por PIs primários e derivados como imagens de satélites, hidrografia, curvas de nível, área urbana, sistema viário, cobertura e uso da terra, Áreas de preservação Permanente, distância às áreas urbanas, adequabilidade com relação à hidrografia, entre outros. Os PIs critérios foram padronizados por meio da lógica fuzzy e, então, analisados com base nos princípios da Avalição Multicritério e cruzados pelo método da Combinação Linear Ponderada. O resultado do modelo proposto é um mapa de adequabilidade à ocupação urbana, composto de quatro classes: muito alta, alta, média e baixa. A razão entre adequabilidade e restrição com relação ao total da área do município é, respectivamente, 34,7\% e 65,3\% (24,02 km² e 45,24 km²). Pode-se concluir que as funcionalidades disponíveis nos SIGs permitiram executar o modelo adequadamente, evidenciando-se, assim, suas potencialidades para a análise espacial.

1 Mestrando em Geografia; Universidade Federal do Rio Grande do Sul, UFRGS, Brasil; Colaborador do LABMODEL RAZ, Universidade Federal do Rio Grande do Sul. Av. Bento Gonçalves, 9.500, Prédio 43130, Porto Alegre - RS, CEP: 91501-970; E-mail: kledson.grabski@ufrgs.br

2 Dra.; Geociências; Universidade Federal do Rio Grande do Sul, UFRGS, Brasil; Professora Associada, Líder do Grupo de Pesquisa Geoprocessamento e membro do Phi-Robotics Research Group; Universidade Federal do Rio Grande do Sul, Instituto de Geociências, Departamento de Geodesia, LABMODEL RAZ. Av. Bento Gonçalves, 9.500, Prédio 43130, Porto Alegre - RS, CEP: 91501-970; E-mail: flavia.farina@ufrgs.br (*) Autor para correnpondências

\begin{tabular}{llllll}
\hline Ambiência & Guarapuava (PR) & v.14 n.2 & p. $282-299$ & Maio/Ago 2018 & ISSN $1808-0251$
\end{tabular}


Palavras Chave: Planejamento Urbano; Adequabilidade à Ocupação Urbana; Combinação Linear Ponderada, Tomada de Decisão.

\section{Abstract}

Currently, urban growth has been set up as a sometimes uncontrolled problem, leading to disorganized and discontinuous expansion, far from safety and sustainability standards. Therefore, this paper aims to propose a spatial model based on GIS to support the recommendation of suitable areas for urban expansion. The implementation of the model used the municipality of Monte Belo do Sul, located in the Serra Gaucha metropolitan region (RS), as a test area. For this purpose, initially-defined criteria representing the necessary characteristics must have an area that may be occupied. Spatialization and modeling of these criteria is carried out in a GIS environment (ArcGIS and IDRISI), where each relevant variable consists of a thematic information plan. Thus, the database is composed of primary and derived layers as satellite images, hydrography, contours, urban area, road system, cover and land use, permanent preservation areas, distance to urban areas, hydrography suitability, among others. Layer criteria was standardized by fuzzy logic and then analyzed based on Multi criteria Evaluation principles and crossed with a weighted linear combination method. The result of the proposed model is a map of suitability for urban occupation, consisting of four classes: very high, high, medium and low. The level of suitability and restriction compared to the total municipal area is $34.7 \%$ and $65.3 \%(24.02 \mathrm{~km} 2$ and $45.24 \mathrm{~km} 2)$ respectively. It can be concluded that the available GIS features allowed the model to be executed adequately, therefore demonstrating their potential for spatial analysis.

Keywords: Urban Planning; Suitability for Urban Occupation; Weighted Linear Combination, Decision Making.

\section{Introdução}

Nas últimas décadas, o crescimento urbano tornou-se um problema, por vezes, sem controle, ocasionando a expansão desordenada e descontínua, alheia aos padrões de segurança e sustentabilidade. Apesar de esses fatores estarem presentes em diversas regiões do mundo, no Brasil, são inúmeros os municípios que enfrentam esta realidade. As frequentes inundações e deslizamentos de terra em áreas urbanizadas e seus efeitos sobre a população e a economia têm mostrado a importância de estudos mais aprofundados para subsidiarem o planejamento e a gestão urbana. Ademais, a ocupação urbana em zonas inadequadas, sob o ponto de vista ambiental, e o controle ineficaz de atividades econômicas que oferecem riscos a população têm trazido à tona a grande dimensão dos prejuízos ambientais, que revertem à própria sociedade.

Santoro (2012) aponta que uma das tentativas de reduzir as consequências da incompatibilidade entre a ocupação do espaço e a aptidão do ambiente foi o estabelecimento de uma série de leis que, embora por vezes tenham sido elaboradas por motivações econômicas e políticas, se constituem em relevantes instrumentos para a solução dos problemas socioambientais das áreas urbanas. 
O conjunto de instrumentos legais voltados à proteção do meio ambiente, é resultado de uma ampla discussão iniciada pelo movimento ambientalista na década de 60 . O questionamento sobre as formas de relação entre sociedade, economia e natureza, a mobilização de comunidades locais e o surgimento de organizações não-governamentais de defesa do meio ambiente conduziram a elaboração de políticas e estruturas públicas específicas para o tratamento da questão ambiental (CASTELLS, 2000). No Brasil, a criação de leis nos níveis federal, estadual e municipal, passaram a normatizar a ocupação dos espaços e estabelecer áreas que devem ser preservadas, protegidas ou serem foco de regimes urbanísticos especiais. Entre elas, pode-se citar a Lei do Parcelamento do Solo Urbano (BRASIL, 1979), o Estatuto da Cidade (BRASIL, 2001); o Código Florestal Brasileiro (BRASIL, 2012) e a própria Constituição Federal (BRASIL, 1988).

Considerando-se a gestão urbana em nível local, para Hoffmann et al (2011) o Plano Diretor é o instrumento que permite implementar o planejamento urbano relacionado com a idealização do futuro de um município e deve estar atrelado ao respeito ambiental. Em sua elaboração, um aspecto a ser considerado é a delimitação de zonas específicas e seus respectivos usos do solo para que seja possível projetar quais ações devem ser exercidas dentro de seus limites e como deve ser o planejamento de sua infraestrutura. Mota (1999) afirma que a concepção de um Plano Diretor necessita contemplar as dimensões ambientais, sociais e econômicas em três etapas principais assim definidas: levantamento de dados, diagnóstico e prognóstico. Nesse contexto, o planejamento urbano definido pelo Plano Diretor está atrelado ao conceito de planejamento ambiental, pois este também constitui um conjunto de metas, objetivos e instrumentos adequados para garantir a viabilidade socioambiental no futuro, tratando-se de uma abordagem estratégica para garantir a preservação e conservação dos recursos naturais e, consequentemente, a sobrevivência da civilização (SANTOS, 2004). Ademais, o planejamento de assentamentos é mais eficaz quando se considera uma perspectiva integrada das características do ambiente natural e as necessidades físicas de expansão.

A integração das dimensões e etapas do planejamento proposta por Mota (1999) e Santos (2004) encontra subsídios no avanço tecnológico das técnicas de Sensoriamento Remoto e os Sistemas de Informação Geográfica (SIG). As ferramentas disponíveis nesses sistemas permitem identificar, mapear, monitorar e estudar os fenômenos naturais e antrópicos, integrando variáveis e otimizando o processo de tomada de decisão (JENSEN, 2009; BURROUGH, McDONNELL, LLOYD, 2015). Através do processamento de imagens de satélites e da modelagem em SIG de variáveis que compõem um problema em específico, é possível prever e/ou minimizar possíveis impactos ambientais ocasionados pela ocupação do território. Assim, a locação de usos do solo no meio urbano tornou-se mais eficiente na medida em que um SIG permite a geração e a análise conjunta de dados estatísticos, mapeamentos, zoneamentos, levantamentos cadastrais, entre outros.

O grande potencial do SIG para o planejamento urbano é o fato de ser caracterizado como ferramenta de apoio à decisão, principalmente em projetos de localização de áreas para determinadas atividades, o que envolve uma variedade de critérios e análises complexas das alternativas possíveis. A avaliação multicritério (Multi Criteria Evaluation - MCE) integra o sistema de suporte à decisão de um SIG e pode ser entendida como um conjunto de conceitos, aproximações, modelos e métodos, para auxiliar, na tomada de decisão, para descrever, avaliar, ordenar, hierarquizar, selecionar ou localizar objetos, baseados em uma avaliação de acordo com vários critérios (DELGADO \& CANO, 2005; JIMÉNEZ, BUZAI, DÍAZ, 2012). Os critérios são representados em um SIG sob a forma de plano de informação (PIs) e se caracterizam como 
fatores ou restrições, sendo que os fatores são aqueles que representam algum grau de adequação de zonas para o objetivo proposto. No caso da expansão urbana, os fatores definem uma medida de adequabilidade para o uso em questão. Por outro lado, as restrições se constituem em critérios que limitam regiões geográficas específicas. O modelo de avaliação, na prática, pode ser expresso em pontuações, valores ou intensidades de preferências com a utilização de técnicas de análise geográfica, como os métodos Booleano, combinação linear ponderada (Weghted Linear Combination - WLC) e média ponderada ordenada (Ordered Weighted Average - OWA) (EASTMAN, 2001; DELGADO \& CANO, 2005).

A escolha do método de avaliação dos critérios é o cerne do modelo de decisão, podendo configurar em uma postura mais rígida, no qual as áreas são consideradas totalmente aptas ou inaptas para o uso urbano (método Booleano), ou em uma postura flexível, onde as áreas aptas resultam em níveis de adequabilidade (método WLC). O método WLC emprega conceitos da lógica fuzzy, em que um critério é classificado de forma relativa, ou seja, é estabelecido um grau de pertencimento a determinada classe dentro de um PI, o que melhor se ajusta com as questões de locação de usos do solo. A combinação de todos os critérios requer a estruturação de um modelo hierárquico para o qual são atribuídos pesos a cada critério estabelecido, resultando em um grau de importância relativa. O procedimento de estimativas dos pesos define a regra de decisão para atingir o objetivo proposto e, nos princípios do método WLC, o resultado final é obtido pela média ponderada de todos os critérios. (EASTMAN, 2001; BURROUGH, McDONNELL, LLOYD, 2015).

Essas funções analíticas de um SIG propiciam, aos planejadores, uma impressão menos subjetiva de qual será o resultado no território de suas decisões ou mesmo produzir diferentes cenários virtuais para avaliar a implementação de políticas ou medidas de planejamento (BOSQUE, 1997). Na atualidade, diversos autores demonstraram, com grande variação de metodologias e técnicas empregadas, o potencial de aplicação dessas ferramentas em estudos de locação de usos do solo no meio urbano (AREFIEV et al, 2015; MOSADEGHI et al, 2015; RODRIGUES, 2013; KESKAR \& KUMAR, 2013; ANCIETO et al, 2012; KERSTEN et al, 2002).

Em vista do exposto, o objetivo deste trabalho é propor um modelo espacial, baseado em análise multicritério e SIG, que permita subsidiar a seleção de áreas adequadas para expansão urbana, ponderando as restrições ambientais e as especificidades da legislação pertinente.

\section{Material e Métodos}

\section{Área de estudo}

A seleção de um município teste para o desenvolvimento do modelo proposto levou em consideração condições ambientais que oferecessem um certo grau de dificuldade para a sua aplicação. Neste sentido, a área de estudo corresponde ao município de Monte Belo do Sul (Figura 1), localizado na Região Metropolitana da Serra Gaúcha (RMSG), no estado do Rio Grande do Sul. O núcleo urbano principal está localizado sobre o topo de um morro, em uma região composta por zonas de alta declividade, encostas abruptas, com uma parcela significativa de áreas cobertas por fragmentos de mata nativa e por usos do solo voltados à vitivinicultura. A população total é de 2.748 habitantes (IBGE, 2010) e uma área aproximada de $69 \mathrm{~km}^{2}$. A RMSG é o segundo conjunto urbano do Estado com mais de 700 mil habitantes e uma das mais 
dinâmicas aglomerações industriais do Brasil. Trata-se de um polo da indústria metalomecânica, concentrando quase $10 \%$ do PIB total do Estado e cerca de 15\% do PIB industrial (IBGE, 2010). Apesar de Monte Belo do Sul ter sua base econômica assentada em atividades rurais e da pequena população, o crescimento urbano também está sujeito às atividades econômicas regionais, podendo trazer impactos futuros aos ambientes naturais que compõem o município. Ainda, devido à reduzida área urbanizada e ao seu Plano Diretor até o momento não apresentar os limites geográficos da zona de expansão urbana, o município pode se valer do benefício de planejar antecipadamente o crescimento da zona urbana consolidada.

\section{Figura 1 - Localização e delimitação da área de estudo.}

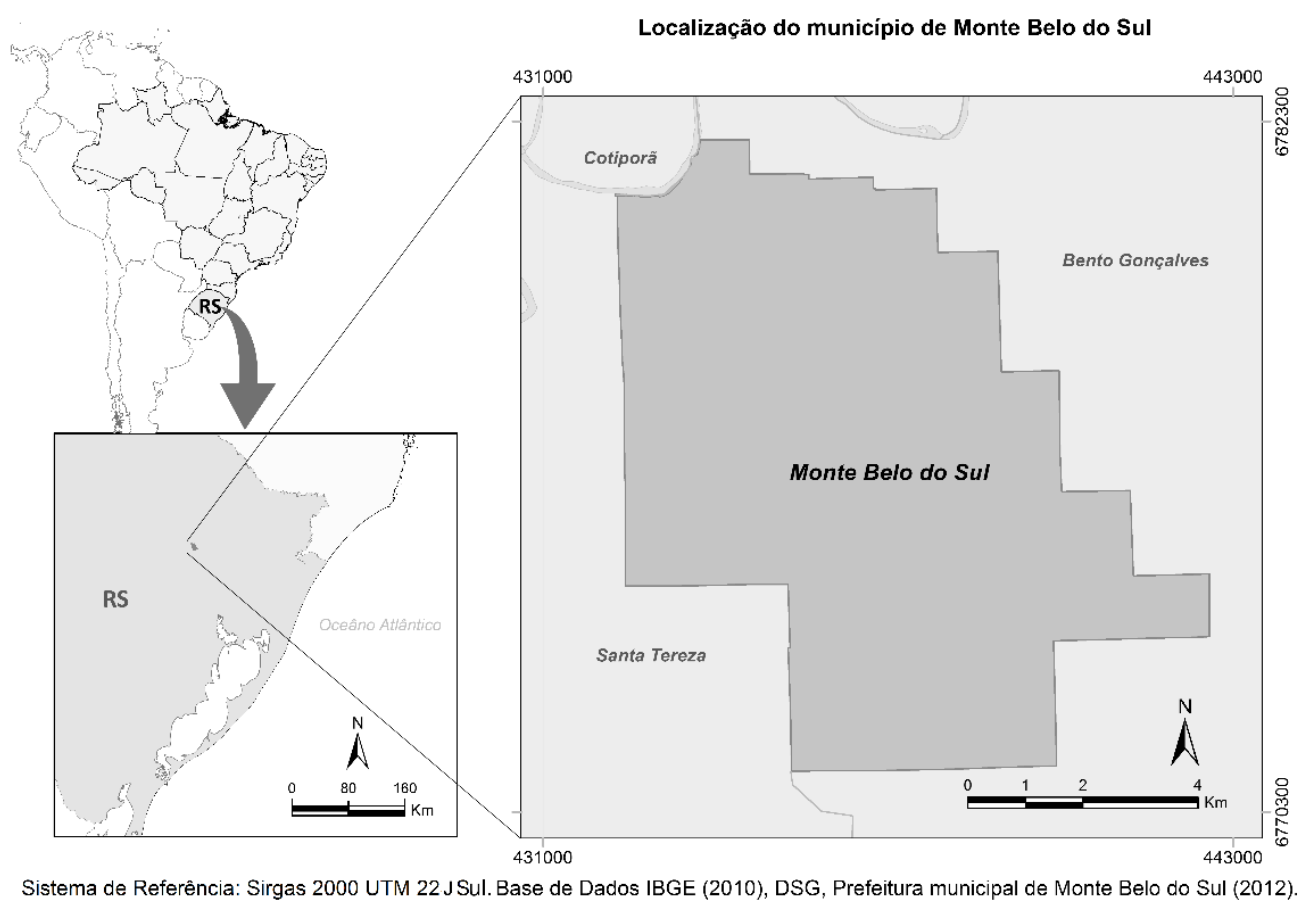

Elaborado por: Kledson Grabski

Fonte: Elaborado pelos autores (2016)

\section{Desenvolvimento do modelo}

A metodologia empregada para o desenvolvimento do modelo envolveu as seguintes etapas principais: estabelecimento dos critérios pertinentes à ocupação urbana; entrada e tratamento dos dados; espacialização e normalização dos critérios; atribuição dos pesos; combinação dos critérios e; simulação e seleção de cenários. A estruturação do banco de dados para entrada, ajuste e edição de informações foram realizados no software ArcGIS 10.2 e a implementação do modelo foi executada no sistema de suporte à decisão do IDRISI TerrSet, de modo que fossem aproveitadas as potencialidades de cada um dos programas.

\section{Definição dos critérios de adequabilidade à expansão urbana}

Os critérios para a seleção de áreas adequadas ao uso urbano podem ser definidos como um conjunto de características que as áreas devem possuir para o uso urbano e, de maneira geral, se fundamentam na otimização dos custos decorrentes da expansão urbana (fatores) e nas 
limitações geográficas ou impostas pela legislação vigente (restrições). A partir destes fundamentos e considerando um diagnóstico físico-ambiental do município elaborado previamente, foram definidos os seguintes critérios fatores: adjacência e proximidade aos núcleos urbanos existentes; contiguidade e acessibilidade à rede viária estabelecida e; conformidade às restrições legais relativas a alterações de ambientes. Por outro lado, os seguintes critérios foram classificados como restrição: áreas externas ao limite do município, núcleos urbanos consolidados, devido ao interesse por sua expansão; áreas ocupadas pela hidrografia existente, pois não é possível ocupar essas áreas; áreas de interesse ecológico e botânico e; áreas que tenham algum tipo de proteção legal para fins de urbanização. Este último critério foi embasado na Lei 12.651 de 25 de maio de 2012 (Código Florestal Brasileiro), apontada no estudo prévio da legislação como aquela que apresenta, nos níveis federal, estadual e municipal, o maior grau de restrição ao uso, bem como estabelece as Áreas de Preservação Permanente (APP). Além disso, apesar de a vegetação nativa não se constituir claramente no Código Florestal como uma categoria de APP, optou-se por incluí-la como uma área de interesse ecológico, devido a postura preservacionista adotada neste trabalho.

\section{Entrada dos dados primários e espacialização dos critérios}

Estabelecidos os critérios, para que possam ser espacializados e avaliados no SIG, foram definidas as variáveis pertinentes e o seus respectivos PIs, descritos na Tabela 1. Esta sistemática facilita a organização de quais informações temáticas são necessárias para a execução do modelo proposto.

\section{Tabela 1: Variáveis e Planos de Informação resultantes dos critérios para expansão urbana}

\begin{tabular}{|c|c|c|}
\hline Critérios & Variáveis & Planos de Informação \\
\hline Região de interesse & Limite município & Área de estudo \\
\hline $\begin{array}{c}\text { Adjacência/proximidade aos } \\
\text { núcleos urbanos }\end{array}$ & Área urbana & $\begin{array}{c}\text { Área urbana consolidada } \\
\text { Distância à área urbana } \\
\text { consolidada }\end{array}$ \\
\hline $\begin{array}{l}\text { Contiguidade/acessibilidade à } \\
\text { rede viária }\end{array}$ & Rede viária & $\begin{array}{c}\text { Vias } \\
\text { Distância às vias }\end{array}$ \\
\hline Exclusão da hidrografia & Hidrografia & $\begin{array}{c}\text { Cursos de água } \\
\text { Corpos de água } \\
\text { Nascentes }\end{array}$ \\
\hline Obedecer a legislação vigente & Legislação (APP) & $\begin{array}{c}\text { Distância aos cursos de } \\
\text { água } \\
\text { Distância às nascentes } \\
\text { Declividade }=\text { ou }>45^{\circ} \\
\text { Topo de morros }\end{array}$ \\
\hline Interesse ecológico/botânico & Vegetação nativa & Cobertura e uso da terra \\
\hline
\end{tabular}


O banco de dados espacial foi estruturado no SIG ArcGIS 10.2, em formato geodatabase, para armazenamento de todos os dados obtidos, oriundos de diversas fontes e formatos, conforme descritos na Tabela 2.

\section{Tabela 2: Características e fontes dos dados primários.}

\begin{tabular}{|c|c|c|c|}
\hline Dado & Formato & $\begin{array}{c}\text { Escala/ Resoluçãao } \\
\text { Espacial }\end{array}$ & Fonte \\
\hline $\begin{array}{l}\text { Limite municipal } \\
\text { Perímetro urbano } \\
\text { Sistema viário }\end{array}$ & $\begin{array}{l}. \mathrm{dwg} \mathrm{e} \\
. \mathrm{kmz}\end{array}$ & $1: 50.000$ & $\begin{array}{l}\text { Prefeitura Municipal de Monte } \\
\text { Belo do Sul }\end{array}$ \\
\hline $\begin{array}{l}\text { Perímetro urbano } \\
\text { Curvas de nível área urbana }\end{array}$ & dwg & $1: 10.000$ & $\begin{array}{l}\text { Prefeitura Municipal de Monte } \\
\text { Belo do Sul }\end{array}$ \\
\hline $\begin{array}{c}\text { Curvas de nível } \\
\text { Pontos cotados } \\
\text { Rede viária } \\
\text { Hidrografia }\end{array}$ & .shp & $1: 50.000$ & $\begin{array}{c}\text { Diretoria de Serviço Geográfico } \\
\text { do Exército Brasileiro (DSG, } \\
\text { 1980) }\end{array}$ \\
\hline $\begin{array}{l}\text { Geologia } \\
\text { Geomorfologia } \\
\text { Pedologia }\end{array}$ &. $\operatorname{shp}$ & $1: 250.000$ & $\begin{array}{c}\text { Instituto Brasileiro de } \\
\text { Geografia e Estatística (IBGE, } \\
\text { 2014) }\end{array}$ \\
\hline Imagem SRTM ${ }^{1}$ & geoTif & 30 metros & $\begin{array}{c}\text { United States Geological Survey } \\
\text { (USGS, 2015) }\end{array}$ \\
\hline $\begin{array}{c}\text { Imagem do satélite } \\
\text { RapidEye (29/08/2013) }\end{array}$ &.$i m g$ & 5 metros & $\begin{array}{l}\text { GeoCatálogo, Ministério do } \\
\text { Meio Ambiente (MMA, 2015) }\end{array}$ \\
\hline Imagens de satélite (2012) &.$j p g$ & Variável & GoogleEarth PRO \\
\hline
\end{tabular}

1Shuthe Radar Topography Mission.

Fonte: Elaborado pelos autores (2016)

Em razão das características diversas e da desatualização, alguns dados tiveram de ser ajustados e referenciados a um mesmo sistema geodésico de referência (SIRGAS2000 e Projeção Universal Transversa de Mercator). Como exemplo, a hidrografia foi ajustada e atualizada por meio de imagens dos satélites RapidEye e SRTM. Esta última serviu como base para a execução dos procedimentos no ArcGIS, onde a drenagem é identificada conforme a topografia do terreno (ferramenta Hidrology). Assim, a hidrografia da base cartográfica e aquela obtida pela modelagem da imagem SRTM foram sobrepostas e ajustadas à imagem RapidEye. Além do ajuste, as nascentes foram identificadas por meio da atribuição de feições de pontos nas coordenadas iniciais de cada drenagem, com auxílio de imagens oriundas do GoogleEarth PRO.

A etapa seguinte se refere à geração dos demais mapas temáticos a fim de atender a espacialização dos critérios adotados.

O mapa de cobertura e uso da terra foi elaborado pelo método da interpretação visual sobre a imagem do satélite RapidEye, onde foram vetorizadas, em uma escala de visualização 1:10.000, as seguintes classes: mata nativa, campo, silvicultura, cultivo agrícola, áreas urbanas, rede viária, cursos d'água e corpos d'água. A definição das classes a serem mapeadas seguiu o Sistema de Classificação proposto pelo IBGE (2013), respeitando a resolução espacial da imagem. Na 
identificação dos alvos, as bandas utilizadas incluem as composições coloridas RGB321 e RBG432, sendo esta última de grande utilidade para a distinção entre a vegetação e os corpos d'água. A banda 4 registra a radiação eletromagnética em um intervalo de 0,69 a $0,73 \mu \mathrm{m}$. Nesse intervalo, a vegetação apresenta uma alta refletância enquanto a água tem uma alta absorção. Esse contraste facilita a diferenciação entre ambos os alvos. Ademais, a composição em infravermelho facilitou a distinção entre a silvicultura e a vegetação nativa, uma vez que, na composição das faixas do visível, houve diversas situações em que estas duas classes se confundiram. Ainda, foram utilizados como apoio neste processo, os dados do IBGE referentes ao censo agropecuário (lavouras temporárias, permanentes e extração vegetal) e a imagem obtida do Google EarthPro.

As Áreas de Preservação Permanente, definidas a partir do Código Florestal, representam, no município em estudo, áreas adjacentes à hidrografia e às nascentes, áreas de topo de morro e as encostas com declividade superior a $45^{\circ}$. A delimitação das APPs de hidrografia consistiu na aplicação de operadores de distância (buffer) sobre o PI de hidrografia, com os seguintes parâmetros definidos pela legislação: 50 metros para as nascentes e para o curso de água com largura entre 10 e 50 metros (Rio das Antas) e, 30 metros para os cursos de água com menos de 10 metros de largura (drenagem permanente e intermitente).

A obtenção das APPs de declividade foi embasada no Código Florestal, onde é estabelecido que áreas com declividade superior a $45^{\circ}$ não devem ser ocupadas. O Plano Diretor do município rege que as restrições se dão a partir da declividade de $30 \%\left(16,7^{\circ}\right)$, porém, optou-se por desconsiderá-lo já que sua promulgação é anterior ao Código Florestal e deve-se obedecer à legislação mais restritiva. Tal categoria de APP foi mapeada mediante o uso de operadores de contexto sobre o modelo digital do terreno (MDT), elaborado a partir das curvas de nível e dos pontos cotados da base cartográfica da DSG.

Um processamento mais complexo, composto por 37 etapas, e fundamentado na metodologia proposta por Oliveira e Fernandes Filho (2013) foi empregado para a obtenção das APP's topo de morro. O processamento teve como dado de entrada a imagem SRTM e diversos procedimentos disponíveis no módulo Hidrology do software ArcGIS.

Com o objetivo de elaborar o PI de restrições a ocupação urbana, necessário nas etapas seguintes do modelo, selecionaram-se todas as classes dos mapas anteriores que representam alguma limitação ao uso considerado. Assim, realizou-se uma superposição sequencial (overlay) das classes APPs, áreas urbanas, rede viária, hidrografia e mata nativa. Obteve-se, então, uma imagem booleana, com atributo 0 para as áreas que representam alguma restrição legal, interesse ecológico ou encontram-se ocupadas pelas áreas urbanas e vias, e atributo 1 para o restante das áreas.

A partir desse ponto, optou-se por realizar os procedimentos no software IDRISI, pois envolvem a manipulação de dados em formato raster e o seu sistema de suporte a decisão é mais prático e intuitivo em relação ao ArcGIS. Assim, os seguintes planos de informação foram importados e/ou convertidos por meio do módulo GIS Analisys: limite municipal, áreas urbanas, rede viária, rio das Antas, nascentes, drenagens (cursos permanentes e intermitentes) e mapa de restrições. Cabe salientar que os PIs referentes à hidrografia correspondem à variável em si, somada a área de restrição imposta pela legislação.

Em razão de alguns critérios considerarem a variável distância como fator para a ocupação urbana, é necessário aplicar operadores de distância sobre os PIs áreas urbanas, vias e hidrografia. Os fatores se referem à maior proximidade de infraestrutura instalada e à maior distância com 
relação à hidrografia. As classes de hidrografia foram separadas em layers distintos já que cada categoria tem um regime de proteção diferente, segundo a legislação. A execução prática consistiu na conversão dos PIs vetoriais para o formato raster e, posteriormente, na aplicação da rotina Distance. O resultado é um arquivo de formato raster numérico, representando uma superfície contínua, onde cada píxel registra o valor de distância linear com relação à variável considerada, conforme observado na Figura 2.

\section{Figura 2 - Planos de Informação de distância aos fatores considerados.}
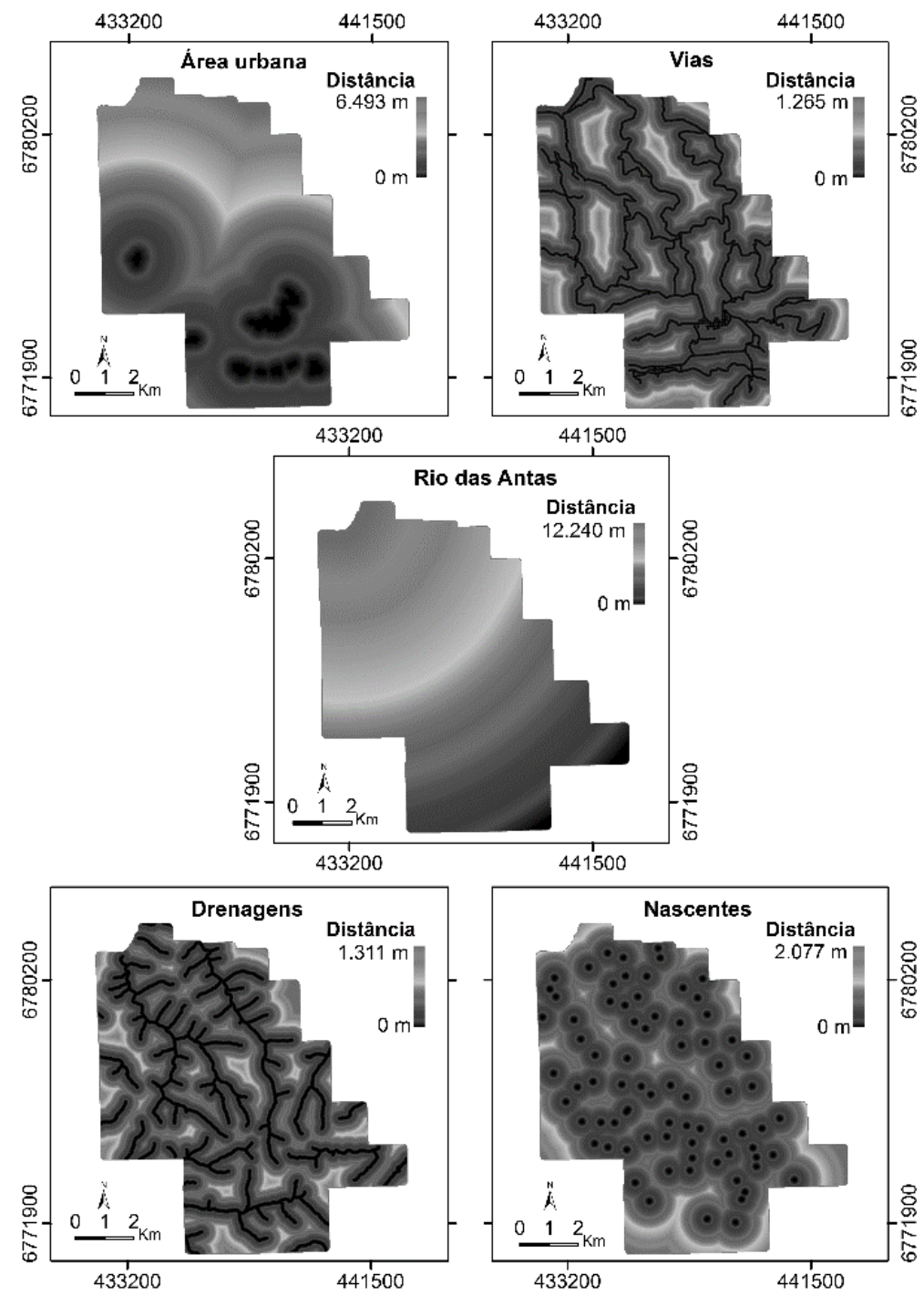

Fonte: Elaborado pelos autores (2016)

\section{Normalização dos Critérios Fatores}

O método WLC utiliza os conceitos da lógica fuzzy, ou seja, cada categoria dos PIs é classificada de forma relativa, onde cada pixel do PI tem um valor associado entre 0 e 255, sendo que os valores próximos ao zero indicam que a área coberta pelo pixel é mais inadequada e quanto mais próximo do valor 255, maior o grau de adequabilidade à finalidade que se tem em vista. O grau de adequabilidade de cada pixel a um determinado objetivo, dentro da lógica fuzzy, é 
definido por meio de funções de pertinência. O IDRISI oferece três formas padrão para as funções de decisão: Linear, Sigmoidal e em forma de J. Estas funções podem ser do tipo crescente ou decrescente e têm sua forma específica definida por dois pontos de controle (Figura 3).

\section{Figura 3: Exemplos de funções de decisão disponíveis no IDRISI}
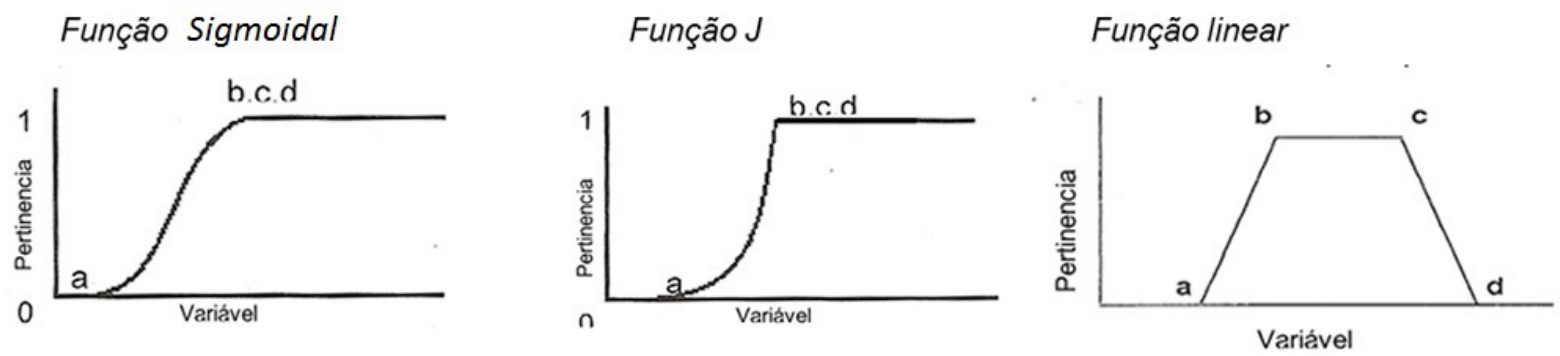

Fonte: Modificado de Delgado e Cano (2005).

A normalização das variáveis, de acordo com as condições de adequabilidade, exige uma postura coerente do analista, o que torna importante a decisão de selecionar a função de pertinência mais adequada ao problema em questão, tanto quanto a natureza desta função como, também, quanto a sua forma mais particular. Neste trabalho, optou-se por aplicar funções que valorizassem a distância aos recursos hídricos e a proximidade da infraestrutura já instalada sem, no entanto, desconsiderar o elevado percentual de áreas que apresentam algum tipo de restrição.

Nesse contexto, para a drenagem e as nascentes, a função sigmoidal crescente representou melhor a classificação gradual de adequabilidade desejada entre as distâncias de inflexão. Considerou-se, para tal, que a proximidade à hidrografia apresenta maior vulnerabilidade, relacionada no município, principalmente à pressão do uso agrícola e, ainda, não há claramente definida uma postura de conservação no Plano Diretor para estas áreas. Assim, diferentes valores foram atribuídos para cada classe, onde o ponto de controle "a” expressa uma padronização com variação suave e o ponto de controle "b" expressa uma variação de adequabilidade intermediária. Ao primeiro ponto foi atribuída a metade da largura da faixa de preservação regida pela legislação e, ao segundo, um valor igual à largura da faixa de preservação. A adoção desses valores objetivou criar, no resultado final, uma área de transição entre adequabilidades, semelhante às zonas de amortecimento em unidades de conservação, onde os usos do solo estão sujeitos a normas e restrições específicas, com o propósito de minimizar os impactos negativos das atividades que ocorrem em seus limites externos.

Por outro lado, a proximidade das áreas urbanas e do sistema viário diminui os custos de expansão dos equipamentos urbanos. Portanto, a função de pertinência linear se mostra a mais adequada, de forma que, até um determinado limite, a variação espacial da adequabilidade é igual (“c") e, a partir deste ponto dado, até um valor final estabelecido (“d”), ela decai abruptamente até atingir o valor zero. Considerando o cenário do município, em termos da área total e urbana atual e da pequena população, estabeleceu-se este último limite em 3.500 metros, ou seja, a partir dessa distância, sob o ponto de vista da economicidade, nenhuma área é adequada. Ademais, 
as vias tiveram um ponto de corte mais estreito, em razão de estarem associadas apenas à rede elétrica, não estando vinculadas a outros serviços urbanos, como rede de água e esgoto. A tabela 3 ilustra a maneira pela qual os PI fatores foram padronizados e a Figura 4 exemplifica os PIs de adequabilidade resultantes.

\section{Tabela 3 - Funções de pertinência e respectivos pontos de inflexão dos critérios fatores}

\begin{tabular}{cccccc}
\hline \multirow{2}{*}{ Classe } & \multirow{2}{*}{ Função } & \multicolumn{5}{c}{ Pontos de inflexão (metros) } \\
& & $\mathbf{a}$ & b & c & d \\
\hline Áreas urbanas & Linear & - & - & 1.500 & 3.500 \\
Vias & Linear & - & - & 500 & 1.000 \\
Rio das Antas & Sigmoidal & 25 & 50 & - & - \\
Drenagens & Sigmoidal & 15 & 30 & - & - \\
Nascentes & Sigmoidal & 25 & 50 & - & - \\
\hline
\end{tabular}

Fonte: Elaborado pelos autores (2016)

Figura 4 - Planos de Informação de adequabilidade à ocupação urbana para os fatores considerados.
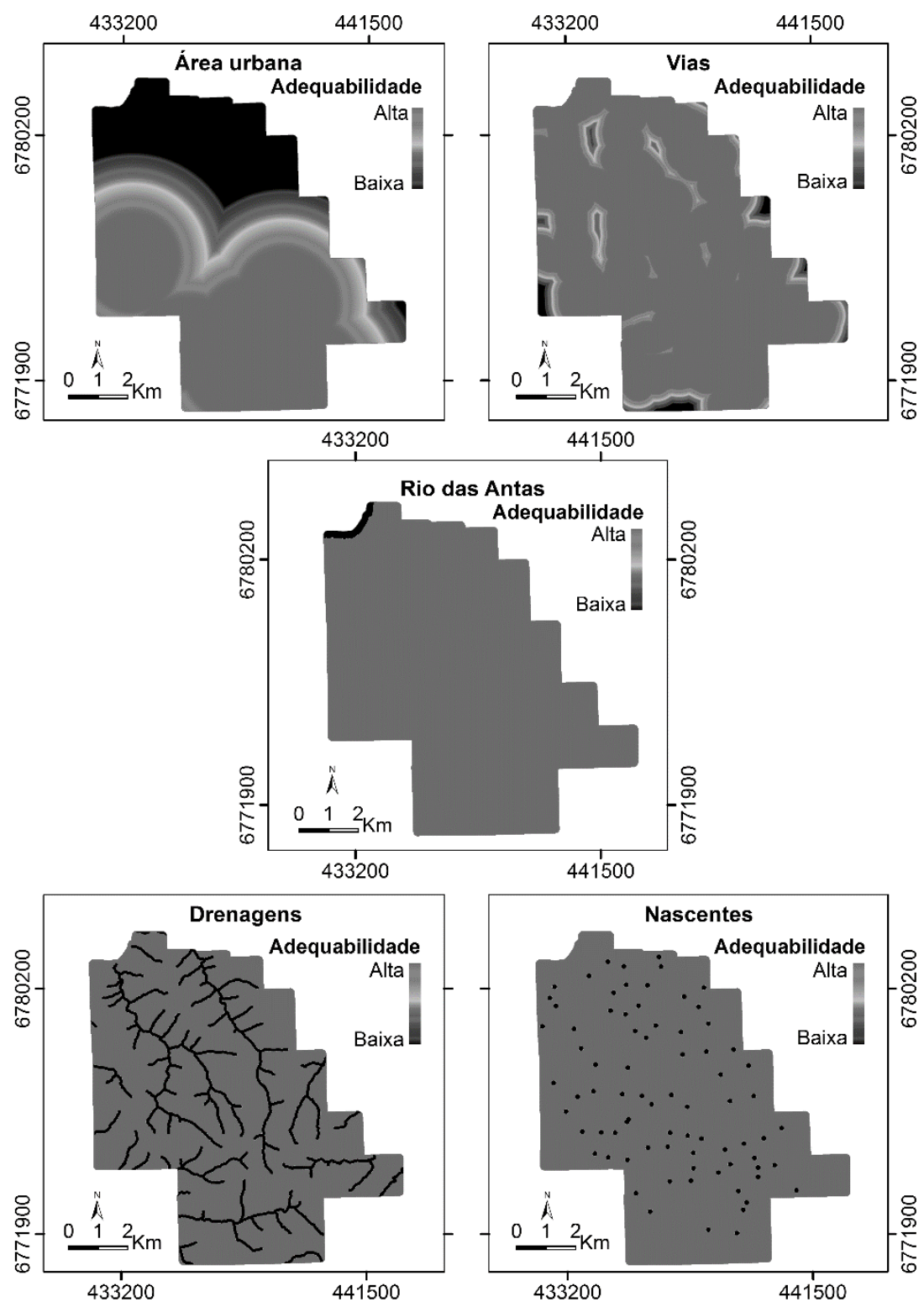
Fonte: Elaborado pelos autores (2016)

\section{Combinação Linear Ponderada}

Como o objetivo deste trabalho visa a tomada de decisão baseada em múltiplos critérios, estes precisam ser analisados e comparados entre si, a fim de se estabelecer uma relação de importância entre as variáveis, ou seja, definir pesos para cada uma delas. Esta etapa foi executada pelo método WLC que utiliza, inicialmente, o Processo de Análise Hierárquica (AHP - Analytic Hierarchy Process) para quantificar a decisão, considerando a importância relativa dos fatores analisados. Os valores são atribuídos com base na escala de importância relativa (Tabela 4) proposta por Saty (1980, apud Delgado \& Cano, 2005) e implementada em uma matriz de comparação pareada. Cada célula da matriz define numericamente a importância relativa da variável situada ao longo da linha, em relação à variável correspondente na coluna, simulando uma matriz de correlação.

\section{Tabela 4 - Escala de importância para o estabelecimento de pesos no Idrisi}

\begin{tabular}{|c|c|c|c|c|c|c|c|c|}
\hline $1 / 9$ & $1 / 7$ & $1 / 5$ & $1 / 3$ & 1 & 3 & 5 & 7 & 9 \\
\hline \multirow[t]{2}{*}{ Extremo } & Muito forte & Forte & Moderado & \multirow[t]{2}{*}{ Igual } & \multirow[t]{2}{*}{ Moderado } & Forte & $\begin{array}{l}\text { Muito } \\
\text { forte }\end{array}$ & Extremo \\
\hline & \multicolumn{3}{|c|}{ - Menor importância } & & & \multicolumn{3}{|c|}{ nportânc } \\
\hline
\end{tabular}

Fonte: Delgado \& Cano, 2005

A elaboração da matriz se deu no software IDRISI, a partir do módulo Decision Support e a Tabela 5 ilustra a postura adotada neste procedimento, valorizando a conservação das nascentes, sem descuidar das necessidades de expansão urbana com as outras áreas sujeitas à preservação.

\section{Tabela 5: Matriz de comparação pareada entre os Pls fatores}

\begin{tabular}{cccccc}
\hline Fatores & $\begin{array}{c}\text { Proximidade } \\
\text { urbano }\end{array}$ & $\begin{array}{c}\text { Proximidade } \\
\text { vias }\end{array}$ & $\begin{array}{c}\text { Distância } \\
\text { Antas }\end{array}$ & $\begin{array}{c}\text { Distância } \\
\text { drenagem }\end{array}$ & $\begin{array}{c}\text { Distância } \\
\text { nascentes }\end{array}$ \\
\hline Proximidade urbana & 1 & & & & \\
Proximidade vias & $1 / 3$ & 1 & & & \\
Distância Antas & $1 / 3$ & $1 / 3$ & 1 & & \\
Distância drenagem & $1 / 3$ & $1 / 3$ & 1 & 1 & \\
Distância nascentes & 3 & 3 & 3 & 3 & 1 \\
\hline
\end{tabular}

Fonte: Elaborado pelos autores (2016)

A implementação da matriz resultou no cálculo dos coeficientes de importância de cada fator (Tabela 6). O índice de consistência aos valores atribuídos na matriz é calculado automaticamente 
e varia entre 0 e 1, com 0 indicando completa consistência. Obteve-se a razão 0,08; portanto, plenamente aceitável.

\section{Tabela 6 - Pesos calculados para os mapas fatores}

\begin{tabular}{cc}
\hline Fatores & Pesos \\
\hline Área urbana & 0,2600 \\
Sistema Viário & 0,1657 \\
Rio das Antas & 0,0830 \\
Demais drenagens & 0,0830 \\
Nascentes & 0,4082 \\
\hline
\end{tabular}

Fonte: Elaborado pelos autores (2016)

Para a obtenção do mapa de adequabilidade, é preciso realizar a combinação ponderada dos PI's gerados e apresentados anteriormente. Este método é fundamentado na multiplicação de cada PI fator normalizado por seu respectivo peso e, a soma dos resultados (módulo MCE no IDRISI).

Os dados de entrada se referem às restrições (limite do município e mapa de restrições) e todos os PIs fatores padronizados. Como resultado, obteve-se um PI de adequabilidade numérico, que consiste em uma superfície contínua de aptidão onde todos os pixels possuem valores que oscilam entre 0 (menor adequabilidade) e 255 (maior adequabilidade). Entretanto, esses valores foram reclassificados, para um melhor entendimento e apresentação dos dados, em quatro classes temáticas de adequabilidade de acordo com os seguintes valores: muito alta (255 a 245); alta (244 a 220); média (219-140) e; baixa (139 a 0). A análise considerou as especificidades do município anteriormente mencionadas e, assim, atribui-se um intervalo curto para as classes muito alta e alta, visando priorizar ainda mais a urbanização em áreas próximas dos núcleos já consolidados.

\section{Resultados e Discussão}

O resultado do modelo proposto é apresentado no Mapa de Adequabilidade à Expansão Urbana do Município de Monte Belo do Sul (Figura 5), onde estão expostas as áreas com potencial a essa finalidade, fundamentado nos critérios estabelecidos neste trabalho. Portanto, as informações pertinentes neste mapa atribuem valores de uso às áreas ainda sem implantação de atividades urbanas em consistência com os critérios estabelecidos. Cabe salientar que este produto 
final se originou a partir de diversas simulações de cenários possíveis, implementadas durante o processo de atribuição de funções de decisão e de pesos aos critérios fatores.

\section{Figura 5: Mapa de Adequabilidade à Expansão Urbana do Município de Monte Belo do Sul}
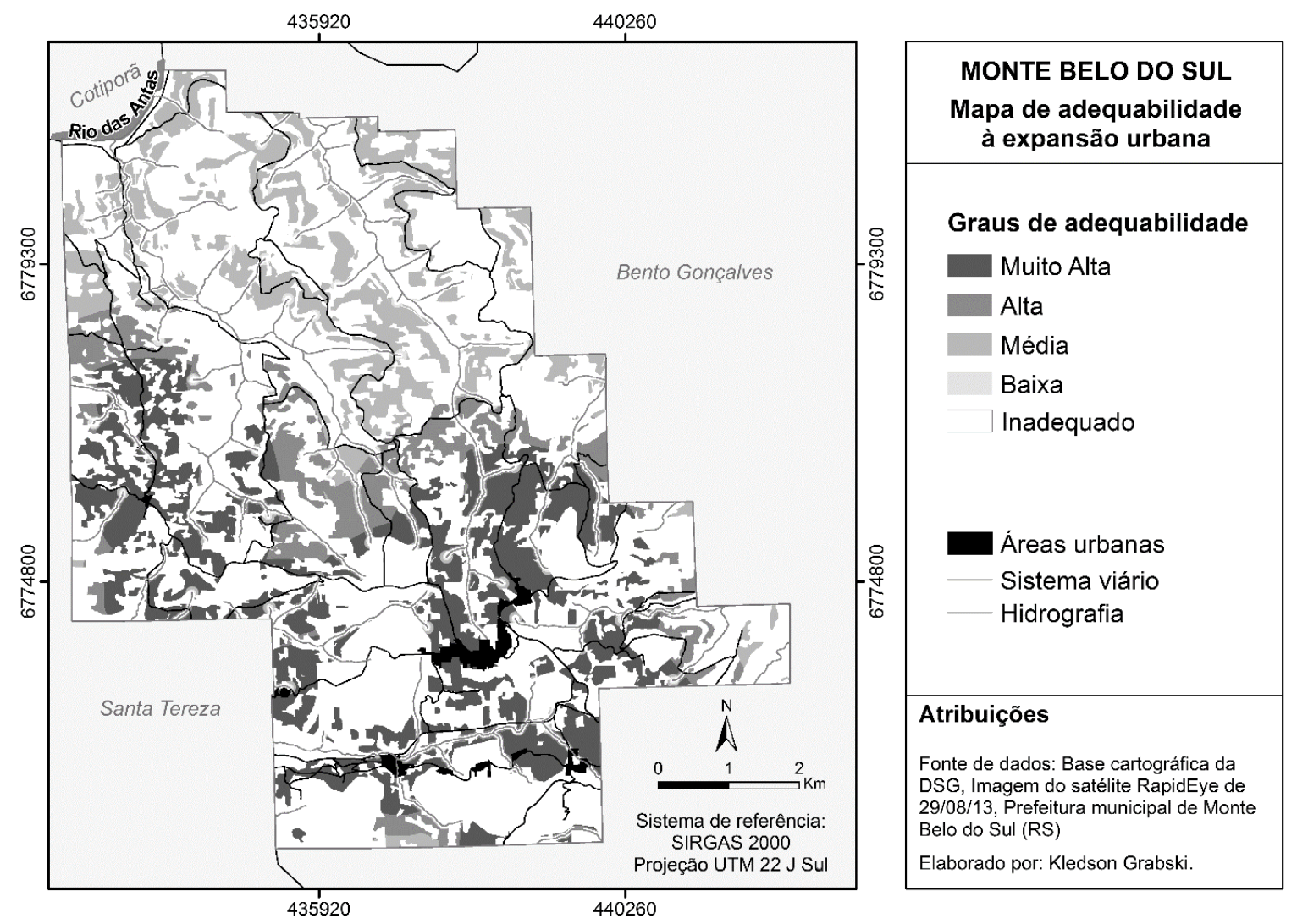

Fonte: Elaborado pelos autores (2016)

A razão entre adequabilidade e restrição, com relação ao total da área do município é, respectivamente, $34,7 \%$ e $65,3 \%$. Pode-se observar que as áreas de muito alta adequabilidade se referem às localizadas mais próximas aos núcleos urbanos e mais distantes da hidrografia, compondo $11,08 \mathrm{~km}^{2}(16 \%)$ da área total do município. Este valor representa quase a metade do total das áreas adequadas e é cerca de 11 vezes maior do que a atual área urbana mapeada. As demais classes tiveram uma representação menor em termo de área devido aos pontos de corte 
no PI de adequabilidade fuzzy, relatados anteriormente. Os valores absolutos e relativos da área de cada categoria podem ser consultados na Tabela 7.

\section{Tabela 7-Valores absolutos e relativos das classes de adequabilidade à ocupação urbana}

\begin{tabular}{ccc}
\hline $\begin{array}{c}\text { Adequabilidade à ocupação } \\
\text { urbana }\end{array}$ & Área $\left(\mathrm{km}^{2}\right)$ & $\begin{array}{c}\text { Relação com a área } \\
\text { total }(\%)\end{array}$ \\
\hline Muito Alta & 11,08 & 16,0 \\
Alta & 4,99 & 7,2 \\
Média & 7,69 & 11,1 \\
Baixa & 0,26 & 0,4 \\
Inadequada & 45,24 & 65,3 \\
\hline Total & 69,26 & 100 \\
\hline
\end{tabular}

Fonte: Elaborado pelos autores (2016)

Outro dado que merece ser mencionado se refere ao total de áreas adequadas para expansão urbana, que corresponde a $24,02 \mathrm{~km}^{2}$, mais de 20 vezes a atual área urbanizada, ou seja, o alto valor de áreas inadequadas obtido $\left(45,24 \mathrm{~km}^{2}\right)$ não oferece entraves maiores para o desenvolvimento urbano. Portanto, pode-se sugerir que as áreas de muito alta adequabilidade devem ser consideradas prioritárias ao uso no processo de expansão urbana.

Analisando-se as classes de média e baixa adequabilidade, percebe-se que elas ocorrem em duas situações: distantes dos núcleos urbanos e/ou muito próximas das nascentes e dos cursos de água localizados dentro de áreas de muito alta adequabilidade. Nesta última situação, é interessante avaliar a sua futura utilização por regimes urbanísticos de menor impacto ambiental, como a criação de áreas específicas como reserva para implantação de praças ou parques públicos. Ademais, as áreas no entorno das nascentes devem receber especial atenção neste aspecto, dado o seu alto valor ecológico para a manutenção da qualidade dos recursos hídricos. Quanto à classe de média adequabilidade houve forte influência da função de pertinência linear aplicada ao PI de distância às áreas urbanas, onde o ponto de corte foi situado em 3.500 metros. Dessa forma, os valores além desta distância, tiveram atribuído um grau de adequabilidade 0 dentro da escala fuzzy.

Quanto às áreas inadequadas para o uso urbano, a variável que mais contribuiu para esta situação é o elevado percentual de mata nativa existente no município. A legislação não restringe totalmente o seu uso, porém, pelas razões já expostas, optou-se em incluí-la nesta categoria. Em segundo lugar estão as APPs topo de morro, cuja ocorrência está diretamente relacionada ao relevo predominante da região. Contudo, certamente o atual Código Florestal reduziu a sua extensão se comparado aos possíveis limites obtidos pela legislação anterior (Código Florestal de 1965 e Resoluções do CONAMA). As demais APPs representaram menores áreas, mas igualmente têm importância para a preservação ambiental.

\section{Considerações Finais}

Os Sistemas de Informação Geográfica utilizados mostraram-se plenamente adequados para o estudo e proposição de áreas para expansão urbana. Apesar de se constituírem em sistemas semelhantes, a operacionalidade dos SIGs ArcGIS e IDRISI se dá de maneira diversa, uma vez que o primeiro é voltado para análise de dados em formato vetorial e o segundo para o formato 
raster. O ArcGIS mostrou-se eficaz na entrada e na organização do banco de dados, modelagem hidrológica, edição e vetorização dos mapas e na representação dos resultados. Por outro lado, o IDRISI possui um sistema de suporte à decisão, mais robusto e prático, exigindo um menor conjunto de procedimentos para a modelagem final.

A execução do método de Avaliação Multi Critério integrada ao SIG é bastante prática e flexível, permitindo alterações na regra de decisão de forma simples e rápida. Ressalta-se que o modelo final é resultado de várias simulações, nas quais foram testadas diferentes funções de pertinência e matrizes de comparação dos critérios, até se atingir o cenário mais apropriado para a realidade do município em questão.

O modelo eleito resultou em um mapa com quatro classes de adequabilidade à ocupação urbana, no qual a classe "muito alta" perfaz $16 \%$ da área do município. Este valor é elevado ao se considerar que representa cerca de 11 vezes a atual área urbana mapeada e a grande quantidade de restrições impostas pelas condicionantes físicas do município. Portanto, após um estudo mais aprofundado junto aos técnicos da Prefeitura Municipal, estas áreas podem vir a se constituir como prioridade para a atualização do Plano Diretor, em especial, no atendimento da demanda quanto à delimitação da zona de expansão urbana.

Quanto aos dados utilizados, alguns pontos devem ser considerados. Pode-se dizer que a etapa de construção do banco de dados consistente é a mais custosa em termos de tempo e a maior dificuldade encontrada se refere à disponibilidade de mapas nos mais diversos formatos e escalas. Variáveis importantes para o modelo proposto estão desatualizadas ou disponibilizadas somente em escalas pequenas ou médias com relação à que deveria ser utilizada no tratamento de questões urbanas, como é o caso da base cartográfica da DSG. Por outro lado, informações de maior escala como as oriundas da Prefeitura Municipal estão disponíveis apenas para a área urbana do munícipio. Constatou-se que esta não é uma realidade exclusiva da região de estudo, mas que a cartografia disponível para o território brasileiro não é adequada às necessidades de mapeamento vinculadas às diversas legislações vigentes. Um exemplo importante diz respeito àdelimitação das APPs de topo de morro, que sofre influência direta do dado de entrada e do método de interpolação empregado. Os limites desta categoria de restrição podem ser superestimados ou subestimados e, ainda, os dados adequados para seu mapeamento deveriam estar em escala maior do que os disponíveis.

Neste sentido, o procedimento de ajuste de escala dos mapas primários e a geração de mapas derivados necessitam de um forte embasamento conceitual das técnicas empregadas e de modelagem do ambiente para evitar a produção de informações equivocadas.

Estudos semelhantes podem ser conduzidos utilizando critérios diversos dos adotados neste trabalho, tais como a inclusão de variáveis que representem algum risco à ocupação urbana (vulnerabilidade à deslizamentos e/ou inundações). Sugere-se ainda uma avaliação cuidadosa da legislação pertinente, utilizando-se aquelas mais recentes e que envolvam hierarquicamente as diversas esferas do poder público. Ademais, os critérios restritivos baseados na legislação variam de acordo com o tipo de ambiente no qual a área de interesse está inserida. Fica evidente, portanto, 
a necessidade de se observarem as especificidades locais em termos de ambientes naturais e de necessidades de expansão urbana.

\section{Referências bibliográficas}

AREFIEV, A.; TERLEEV, V.; BADENKO, V.. GIS-based Fuzzy Method for Urban Planning. Procedia Engineering.v.117,p.39-44,2015.DOI:10.1016/j.proeng.2015.08.121

BRASIL. Constituição (1988). Constituição da República Federativa do Brasil. Brasília, DF: Senado, 1988.

Senado, 2012.

Lei no 12.651, de 25 de Maio de 2012. Novo Código Florestal. Brasília, DF:

Lei ${ }^{\circ} 6.766$ de 19 de Dezembro de 1979. Parcelamento do Solo Urbano e outras Providências. Brasília, DF: Senado, 1979.

BURROUGH,P. A.; McDONNELL, R. A.; LLOYD, C. D. Principles of Geographical Information Systems. Third Edition. Oxford: Oxford University Press, 2015

CASTELLS, M. O poder da identidade. Tradução Klauss Brandini Gerhardt. 2a. Edição. São Paulo: Paz e Terra, 2000.530p.

DELGADO, M. G. CANO, J. I. B.. Sistemas de Informacion Geográfica y evaluación multicritério em la ordenación del território. 2a ed. RA-MA editorial, Madrid, 2005.

DSG. Diretoria do Serviço Geográfico do Exército. Carta Topográfica do Município de Bento Gonçalves SH22-VDII2. 1980.

EASTMAN, R. J. Guide to GIS and image processing. Volume 2. Release 2. Worcester: Clark Labs, Clark University, 2001.114p.

IBGE, Instituto Brasileiro de Geografia e Estatística. Levantamento de Recursos Naturais. Vol.33, Folha SH 22, Porto Alegre e parte das folhas SH 21 e SI 22 Lagoa Mirim. Rio de Janeiro, 1986, 796p.

. Mapas: Cartas Temáticas 1:250.000 Disponível em: $<$ http://mapas.ibge.gov.br/ bases-e-referenciais/cartas-tematicas $>$. Acesso em: 05 de maio de 2015.

HOFFMANN, R. C.; MIGUEL, R. A. D.; PEDROSO, D. C. A importância do planejamento urbano e da gestão ambiental para o crescimento ordenado das cidades. Revista de Engenharia e Tecnologia v 3, n 3, Dez/2011.

JENSEN, J. R., Sensoriamento Remoto do ambiente: uma perspectiva em recursos terrestres / John R.Jansen: Tradução: José Carlos Neves Epiphanio (coordenador)... [et al] - São José dos Campos, SP: Parentese, 2009. 
JIMÉNEZ, A. M.; BUZAI, G. D.; DÍAZ, M. F.. Sistemas de Información Geográfica: aplicaciones em diagnósticos territoriales y decisiones geoambientales. Madrid: RA-MA, 2012. 427p.

KERSTEN, G.E.; MIKOLAJUK, Z.; GAR-ON YEH, A.. Decision Support Systems for Sustainable Development: A Resource Book of Methods and Applications. International Development Research Centre (IDRC) and Kluwer Academic Publishers. 2002. ISBN 0-306-47542-1. Disponível em: < https://idl-bnc.idrc.ca/ dspace/bitstream/10625/24923/1/IDL-24923.pdf >. Acessado em: 12 ago. 2016.

KESKAR, Y.M.; KUMAR, S... Need of Remote Sensing and Geographical Information System in Urban Planning, a Case of Housing Colony in Bhopal City, Madhya Pradesh, India. In: International Journal of Engineering Research \& Technology, Canadá, v.2, Issue 10, p. 1752-1757, ISSN 2278-0181, 2013. Disponível em: <http:// www.ijert.org/view-pdf/5748/need-of-remote-sensing-andgeographical-informationsystem-in-urban-planning-a-case-of-housing-colony-inbhopal-city-madhya-pradeshindia>. Acessado em: 17 mai. 2016.

MMA, Ministério do Meio Ambiente. Geo Catálogo MMA. Disponível em: < http:// geocatalogo.mma.gov.br>. Acessado em: 29 de maio de 2015.

MOSADEGHI, R. WARNKEN, J. TOMLINSON, R. MIRFENDERSK, H. Comparison of Fuzzy-AHP and AHP in a spatial multi-criteria decision making model for urban land-use planning. Computers, Environment and Urban Systens. v. 49, p. 54-65, 2015. DOI:10.1016/j.compenvurbsys.2014.10.001

MOTA, S. Urbanização e Meio Ambiente. Rio de Janeiro: ABES, 1999.353p.

PREFEITURA MUNICIPAL DE MONTE BELO DO SUL, RS. Lei no 745/2006 de 05 de Outubro de 2006.. Plano Diretor do Município de Monte Belo do Sul - RS. Disponível em: <http://leismunicipa.is/prcjh >. Acesso em: 6 de abril de 2015.

RODRIGUES, V.L. Sistema de apoio à gestão urbana estruturado em SIG: Aplicação em Jaú - SP. 2013. 143 f. Tese (Doutorado em Ciências). Programa de Pós-graduação em Geotecnia, Universidade de São Paulo, São Carlos, 2013. Disponível em: <http://www. teses.usp.br/teses/disponiveis/18/18132/tde -28112013-162846/pt-br.php>. Acessado em: 19 set. 2015.

SANTORO, P. F. Marcos legais para a política urbana e ambiental. In: Planejar a expansão urbana: Dilemas e Perspectivas. Tese. Universidade de São Paulo. São Paulo Jan. 2012.

SANTOS, R. F. dos. Planejamento ambiental: Teoria e Prática. São Paulo: Oficina de Textos, 2004.

USGS, UNITED STATES GEOLOGICAL SURVEY. Earth Explorer Disponível 